\title{
The Evaluation Mechanism of Rural Teenagers' Legal Education
}

\author{
Xiaoping $\mathrm{Yu}$ \\ Northwestern Polytechnical University Xi'an, Shanxi Province, China \\ wd81119075@163.com
}

Keywords: Country; teenager; legal education; evaluation mechanism

\begin{abstract}
The popularization of legal education helps to improve Chinese whole legal quality in the youth legal education, and provides objective basis for the evaluation effect of the legal education group. The evaluation mechanism of rural teenagers' legal education is an important part of the process of legal education. It reflects the actual effect of the implementation of $n$ of teenagers. The thesis mainly discusses the evaluation system of legal education in rural areas from the aspects of connotation, function and method.
\end{abstract}

\section{Introduction}

The imbalance of legal construction work leads to the lag of legal education in rural areas. Especially in remote rural areas, constrained by the factors of backward economy and block traffic, it is difficult for rural adolescents to accept legal education. There is a big gap of ability of understanding the law, obeying the law and using the law between rural adolescents and urban youth. It has seriously affected rural adolescents' ability of protecting their rights, and is harmful to preventing and reducing the rate of juvenile delinquency. The present situation of Legal education in rural areas will directly affect the realization of Country under the rule of law. So it is imperative for them to accept legal education. Evaluation mechanism is an important part of the system of legal education in the countryside. It has important practical significance to improve the legal quality of adolescents in rural areas, adjust the education behavior of educators, and improve the education process. Eventually, the evaluation mechanism of rural teenagers' legal education will contribute to make the legal system education into effect.

\section{The connotation of evaluation mechanism of rural teenagers' legal education}

According to certain values or educational goals, evaluation mechanism uses scientific and feasible methods, through systematically collecting information, analyzing and explaining information, make the value judgment on the phenomenon of education, so as to provide the basis for the continuous optimization of education and educational decision-making[1]. Evaluation mechanism of rural teenagers' legal education is a clear objective, systematic and comprehensive evaluation for legal education of young people in rural areas. It take the rural teenagers' legal education as the object of evaluation, the goal of legal education as the basis for evaluation, evaluate the process of legal education and the results obtained by scientific evaluation methods.

First, the evaluation system of rural teenagers' legal education treat the whole process of the legal education and the educational effect as the object of evaluation. Legal education is to develop students' legal literacy, any results require the continuation of a process, once the implementation process of the legal education deviation or problem, then would not have made ideal effect. Therefore, the object of education evaluation mechanism, in addition to the effect of education, the process of legal education is also very necessary. Therefore, the evaluation system of legal education in rural areas can not be used as a single evaluation object, the education process should also be included in the evaluation system.

Second, the evaluation mechanism of legal education is an integral part of education. The evaluation mechanism of legal education is an organic component of the rural legal system education. It is not only the special value of the education evaluation mechanism, but also the unique value of the legal education evaluation mechanism. Legal education evaluation mechanism 
is not independent of the legal education of teenagers, it is a part of the legal education of rural youth. If consciousness to be independent from the legal education for teenagers, and even the above the legal education, it will lose the evaluation of foundation and soil, would not constitute a real evaluation, thus losing the legal education evaluation of the significance and the true purpose.

Third, the rural juvenile legal education is to education activities for rural young students, it in exert a subtle influence on education activities will affect the object of education, legal knowledge, is fuzzy, the characteristics of the potential, uncertainty. Due to its evaluation standards, education effect is difficult to quantify the specific, but as a kind of objective evaluation criteria, its scientific nature can still ensure a qualitative assessment or description to accept the legal education of young people in rural areas, eventually can fully reflect the change and development of young people in rural areas.

\section{The role of rural youth legal education evaluation mechanism}

\section{Guiding role}

The guiding function of education evaluation is the effect and power that the evaluation object has on its own, which can guide the evaluation object to the set goal, which is determined by the direction of the evaluation criteria [2]. In the legal education evaluation, whether it is and the distribution of the formulation of the scheme evaluation, the weight of evaluation index, the evaluation index system of the establishment, evaluation is the final effect, the school implement legal education, improve the legal literacy of teenagers, will play a crucial role in guiding. The guiding function of the evaluation system of the legal education is to guide the students to advance the efficiency and power of the educational goals based on the basic judgment of the process and effect of education. To from the legal norms to guide function starts to deviate from the track of student of science education and effective guidance to enable them to under the guidance of legal norms to form the legal consciousness, develop good standards of behavior and attitude, try to reduce or even avoid the occurrence of adverse consequences.

\section{Identification effect}

Identification refers to the evaluation and determination of the pros and cons of things. The identification based on the educational evaluation is a common existence in educational activities. The appraisal function of the educational evaluation mainly refers to the function of the educational evaluation to determine the level of the target and the difference between them. It is mainly through the collection, collation, analysis, judgment and operation mechanism of the relevant information of the educational evaluation object, which can be achieved through the use of the evaluation tools such as inspection, comparison, judgment and so on [3]. It can be said that the identification is the identification and evaluation of the results of education. The appraisal function of the legal education appraisal is the evaluation result obtained by the legal education appraisal activity. The inherent characteristics of the evaluation itself determine the legal education evaluation mechanism for rural youth legal education has the role of identification. Appraisal function can make people in the evaluation process, according to the legal education activities and make a precise judgment of its progress. And legal education evaluation mechanism reflects the identification function refers to the evaluation mechanism of legal education activities to make rational judgments, it can observed in the process of legal education activities to show the advantages and characteristics, also can timely found activity in the presence of problems and to determine possible.

\section{Diagnostic role}

The diagnostic role of rural youth legal education evaluation is made according to the expected target evaluation system and the evaluation standard and be evaluated object related information is obtained through the use of technology and means of evaluation, and carries on the statistical analysis, to get the appraisal results to be interpreted. Legal education evaluation mechanism can make the reasonable value judgment according to the set of evaluation criteria, so education evaluation not only in order to obtain data, ranking and the results, more important is through evaluation mechanism diagnosis problem, find out the reasons, the correct way of thinking and method. The process of education evaluation as the doctor, only through careful scientific diagnosis 
was "an antidote against the disease". Rural youth legal education evaluation mechanism of the legal education of young people in rural areas has diagnosis function, legal education evaluation mechanism reflects the diagnosis function is to evaluate the mechanism in a comprehensive understanding on the basis of legal education activities, for next step development and gives reasonable suggestions for improvement and make appropriate adjustments.

\section{Rural youth legal education evaluation mechanism method}

The evaluation mechanism of the rural youth legal education refers to the specific methods, means and methods used in the evaluation of the legal education in rural areas. Including the determination of evaluation index weight, collecting, sorting, analysis and evaluation of the data, the evaluation results of the final judgment of the value and other related work methods, means and methods, etc [4]. adolescents in rural areas of legal education evaluation also should be so, it has diversity and integration, not only a method can the final education result finalised.

First, the combination of qualitative assessment and quantitative evaluation. The current evaluation of the legal education mainly uses the index evaluation method, which emphasizes the quantification of the content of the evaluation. As a starting point, the complex educational activities are simply abstracted as a few quantifiable indicators. The quantitative evaluation method of easily lead to evaluation method, the content and the scope is very limited, will lead to some evaluation criteria and indicators of the trend of abstract and conceptual, and quantitative evaluation itself is quite subjective. From this, some scholars put forward the fuzzy evaluation method, which is the standard of qualitative evaluation. However, there are many problems in the qualitative evaluation method, and the subjectivity and fuzziness of the evaluation itself will affect the orientation of the evaluation. Therefore, it is scientific and reasonable to use the method of qualitative analysis and quantitative method to evaluate the legal education of rural youth.

Second, the combination of self evaluation and evaluation of others. Self assessment and assessment are often used in the traditional evaluation methods, but there is still a need to improve and perfect the evaluation process of rural juvenile legal education. Based on the understanding of some kind of angle, the understanding of the subjectivity of the evaluation subject will be limited to the understanding of the self assessment and the assessment of his. Schools, teachers, families, rural grass-roots organizations, government, society can be regarded as the main body of the evaluation of Rural Youth Legal Education results. The family as the basis and important part of the legal education, the evaluation of the school's legal education results on the school's development to ride a decisive role. These evaluation subjects are the main participants in his assessment. In the four aspects of government, society, school, parents evaluation, the school as the main force of education, the evaluation of the legal education of teenagers reflects the evaluation methods of the combination of self assessment and evaluation.

At last, process evaluation and result evaluation are combined. Process evaluation and result evaluation, mainly aimed at the content of evaluation. The construction process of legal education in rural areas is constantly developing and changing, and only the evaluation process of evaluation results and development process can be the most real and objective evaluation. The rural youth legal education should pay more attention to the process and the result of the unification. In order to make the evaluation mechanism of the rural youth legal education can ultimately have a positive impact on the sustainable development of the legal education, and truly promote the development of the purpose of evaluation, it is to do with the process of evaluation and evaluation of the results of the combination.

\section{Conclusions}

Legal construction work is very important to legal education in rural areas. Especially the construction of the evaluation system provides guidance,identification and diagnostic role for the rural legal education. Therefore,in practice, we should strengthen the construction of rural youth legal education evaluation mechanism. Specifically, we should implement the three combinations . 
They are qualitative assessment and quantitative evaluation, self evaluation and evaluation of others, process evaluation and result evaluation.

\section{References}

[1] Huang Xiaoping, Hu Zhongfeng. On the validity of educational evaluation and its construction [J]. Higher education exploration, 2014(02):13-17.

[2] Zhang Yizhong; Xiao Weiping, Xie Meihua, Theory and Practice of Education Evaluation[M]. Higher Education Press, 2012:06.

[3] Wang Jianping, Qi Mei, Educational Administration[M]. Tsinghua University Press, 2012:08.

[4] Zhao Min, The Reseach the innovation on the college moral education in the new media environment[M]. Shandong People's Publishing House, 2012:192. 